\title{
Los frágiles cimientos del presente. La genealogía nietzscheana y la verdad de la historia ${ }^{1}$
}

\author{
JOSÉ MANUEL ROMERO CUEVAS
}

Nietzsche, el pensador intempestivo, que se concebía a sí mismo como «dinamita», como decisión «contra todo lo que hasta este momento se había creído, exigido, santificado» ${ }^{2}$, que recomendaba vivamente la lectura de «biografías en cuya portada tendría que estar inscrita esta leyenda: «Uno que luchó contra su época» ${ }^{3}$, concibió la posición del auténtico pensador en relación a su tiempo de manera coherente con su autopercepción intelectual. Efectivamente, puede sostenerse que para Nietzsche una de las señales distintivas de los nuevos y necesarios filósofos es el antagonismo respecto a su época. Un antagonismo que en numerosos textos nietzscheanos está íntimamente emparentado con un abocamiento a un porvenir que debe alcanzar cumplimiento. Es cierto que en el joven Nietzsche la oposición a la propia época se sustentaba en las experiencias intempestivas generadas por la vivencia de la constelación que establecen la coyuntura histórica actual y la Grecia Clásica. El contraste de nuestro presente con lo realizado ya en la Antigüedad produce una especie de shock, una experiencia radicalmente extrañada respecto al presente en la que se disuelve la percepción petrificada y vinculante de éste. $\mathrm{Cu}$ -

\footnotetext{
${ }^{1}$ Quiero agradecer a los profesores Juan Antonio Nicolás, Remedios Ávila y Armando Segura y a Gabriel Cabello, Antonio Gaitán, Gustavo Galván, Fernando González de Requena, José Luis Moreno y Manuel Sánchez la lectura y comentario de una primera versión de este texto. Este trabajo recoje y desarrolla argumentos expuestos en J.M. Romero, El caos y las formas. Experiencia, conocimiento y verdad en F. Nietzsche, Comares, Granada, 2001, cap. 6, p. 271 y ss. En esta obra puede encontrarse un análisis sistemático de la problemática de la verdad en el pensamiento de Nietzsche. Sus tesis fundamentales aparecen en «Verdad, ficción y cosificación en F. Nietzsche», Universitas Philosophica, n 34-35, Junio-diciembre 2000, Santafé de Bogotá, p. 229-255.

${ }^{2}$ Ecce homo, Alianza, Madrid, 1971 (=EH), p. 123 (KSA VI 365).

${ }^{3}$ De la utilidad y los inconvenientes de la historia para la vida, en F. Nietzsche, Antología, ed. J. B. Llinares, Península, Barcelona, 1988 (=UP), §6, p. 87 (KSA I 295).
} 
riosamente la mirada al pasado repercute en el presente con una fuerza que lo transciende hacia un futuro al fin posible: «sólo en cuanto pupilo de tiempos más antiguos, en particular de la Antigüedad griega, he llegado a tener experiencias tan intempestivas en tanto que soy hijo de la época actual. Este punto tengo, por lo menos, derecho a concedérmelo por mi profesión de filólogo clásico: pues no sé qué sentido podría tener la filología clásica en nuestra época, si no es el de obrar de una manera intempestiva es decir, contraria al tiempo y, por esto mismo, sobre el tiempo y en favor, así lo espero, de un tiempo futuro» ${ }^{4}$. El filósofo debe, desde la perspectiva de Nietzsche, expresar, difundir, propagar a manos llenas su «profundo conocimiento» de la degradación que es el presente, conocimiento al que accede en tanto que poseedor de esas experiencias intempestivas respecto a la propia época, reportadas por un contacto con lo realizado y perdido en la Antigüedad que la filología proporciona ${ }^{5}$. Expresando tal íntimo conocimiento de la barbarie imperante, piensa Nietzsche, se generará la necesidad de combatirla, la cual bastará para provocar la praxis requerida. Pues, como sostiene Nietzsche, «de la fuerte necesidad surgirá un día la acción fuerte» ${ }^{6}$.

El Nietzsche maduro en cambio considera que la condición de posibilidad de que el intelectual se distancie críticamente de lo vigente, de lo establecido como canónico, no es tanto el contacto productivo con lo excelente realizado en el pasado pero ahora perdido sino una determinada configuración de la propia subjetividad, una subjetividad marcada por la enfermedad. La enfermedad es para Nietzsche un auténtico medio de conocimiento ${ }^{7}$ y el gran dolor un maestro de la sospecha, condición de todo auténtico saber: «Sólo el gran dolor es el libertador último del espíritu, el pedagogo de la gran sospecha» ${ }^{8}$.

${ }^{4}$ UP Prefacio, p. 56 (KSA I 247).

${ }^{5}$ En tanto que la filología asume «lo antiguo como un modelo a imitar y continuar», G. Vattimo, Introducción a Nietzsche, Península, Barcelona, 1987, p. 18. Esta concepción de la filología del joven Nietzsche está emparentada con el tipo de orientación al mundo griego promovida por el clasicismo alemán cuyo sentido, además de un «distanciamiento frente al predominio de la cultura francesa», fue expresamente «la crítica del presente» por el contraste con la recuperación de «un mundo diferente y mejor»; E. Nolte, Nietzsche y el nietzscheanismo, Alianza, Madrid, 1995, sobre todo el apartado titulado «La Antigüedad como paradigma y como pasado», p. 105 y ss. Sobre esta cuestión ver R. Ávila, Nietzsche y la redención del azar, Universidad de Granada, Granada, 1986, sobre todo el capítulo «El diagnóstico de Nietzsche acerca de la cultura de su tiempo», p. 93 ss. y M. Barrios, Hölderlin y Nietzsche, dos paradigmas intempestivos de la modernidad en contacto, Reflexión, Sevilla, 1992, p. 21 ss.

${ }^{6} \mathrm{UP} \S 4$, p. 76 (KSA I 278).

${ }^{7}$ Humano, demasiado humano, Akal, Madrid, 1996 (=HH), I, Prólogo, § 4, p. 38 (KSA II 17). En otro lugar sostiene: «La enfermedad fue la que me condujo a la razón», EH p. 41 (KSA VI 283).

${ }^{8}$ La gaya ciencia, M.E. Editores, Madrid, 1994 (=GC), Prólogo, 3, p. 39 (KSA III 350). 
La enfermedad y el dolor posibilitan un distanciamiento por parte del cognoscente del tipo de experiencia común ligada a la forma ordenada y racionalizada de vida para abrirlo a lo problemático, lo rechazado, lo reprimido, aquello que la cultura vigente elude: «estamos agradecidos a la necesidad y a la variable enfermedad, porque siempre nos desasieron de una regla cualquiera y de su «prejuicio» ${ }^{9}$. Esto hace del hombre de conocimiento un ser situado al margen, en una experiencia privilegiada de lo problemático velado para la perspectiva común, lo abre a un «reino gigantesco, casi nuevo todavía, de conocimientos peligrosos: $-i y$ de hecho hay cien buenos motivos para que del mismo permanezca alejado todo el que pueda!» ${ }^{10}$. El distanciamiento de la perspectiva común posibilitado por la enfermedad está relacionado con la apertura de un nuevo reino de conocimientos peligrosos. La enfermedad es, así, un factor de disolución de lo estable y normalizado y, en consecuencia, un factor capaz de generar nuevos desarrollos, con poder para abrir nuevas posibilida$\operatorname{des}^{11}$.

La corrupción y la degradación que es para Nietzsche la enfermedad es lo posibilitante del extrañamiento del pensador respecto a la normalidad constituida en su época, es lo que posibilita que el filósofo pueda ser, tal como sostiene Nietzsche, la mala conciencia de su tiempo ${ }^{12}$. Ahora bien, el filósofo puede ser la mala conciencia de su época en tanto que su mirada apunta a un futuro que el presente obstruye y niega: «el filósofo, en cuanto es un hombre necesario del mañana y del pasado mañana, se ha encontrado y ha tenido que encontrarse siempre en contradicción con su hoy: su enemigo ha sido siempre el ideal de hoy» ${ }^{13}$. Este abocamiento cuasi-utópico del filósofo al futuro es referido por Nietzsche mediante fórmulas ciertamente memorables. Se refiere a sí mismo y al tipo de pensadores por los que aboga como: «Nosotros los nuevos, los que no tienen nombre, los difíciles de entender, nosotros, partos prematuros de un futuro no verificado todavía» ${ }^{14}$. Los filósofos son de ese tipo de hombres «que saben que reflejan el futuro en su rostro» ${ }^{15}$.

¿Qué tipo de trabajo intelectual caracteriza al filósofo en el planteamiento de Nietzsche, un ser abocado a un futuro que ya despunta como una aurora

9'Más allá del bien y del mal, Alianza, Madrid, 1972 (=MB), §44, p. 70 (KSA V 62).

${ }^{10}$ MB §23, p. 46 (KSA V 38).

${ }^{11}$ Cf. G. Campioni, «Las ambigüedades de la liberación en la filosofía de Nietzsche», ER. Revista de Filosofía, 14, 1992/I, p. 80 ss.; T. Mann, Schopenhauer, Nietzsche, Freud, Bruguera, Barcelona, 1984, p. 118 ss.; S. Zweig, La lucha contra el demonio (Hölderlin-Kleist-Nietzsche), El Acantilado, Barcelona, 1999, pp. 249-261.

${ }^{12}$ MB $\$ 212$, p. 156 (KSA V 145).

${ }^{13}$ Ibid.

${ }^{14} \mathrm{GC} \S 382$ (KSA III 635). En otro lugar habla de «Nosotros los europeos de pasado mañana, nosotros primicias del siglo XX» MB §214, p. 161 (KSA V 151).

${ }^{15} \mathrm{GC} \S 161$ (KSA III 497). 
inminente? A primera vista, y de una manera aparentemente paradójica, Nietzsche atribuye al intelectual contrario a su tiempo un trabajo subterráneo. Efectivamente, Nietzsche se refiere a sí mismo como alguien que ha «nacido para una existencia subterránea y combativa» ${ }^{16}$. Pero, ¿qué hace el filósofo en el subsuelo?, ¿en qué sentido es combativo su trabajo allá abajo? El magnífico texto con el que se abre el prólogo a Aurora, y que merece ser citado por entero, puede aclararnos algo acerca de esta cuestión: «Este libro es obra de un hombre subterráneo, de un hombre que taladra, que socava, que roe. Quien tenga los ojos acostumbrados a estas actividades subterráneas podrá ver con qué delicada inflexibilidad va avanzando lentamente el autor, sin que parezca afectarle el inconveniente que supone estar largo tiempo privado de aire y de luz. Hasta se podría pensar que le satisface este oscuro trabajo suyo. Cualquiera diría que le guía una determinada fe, que un cierto consuelo le compensa de su labor. Pero, ¿no será que quiere rodearse de una densa oscuridad que sea suya y nada más que suya, que trata de adueñarse de cosas incomprensibles, ocultas y enigmáticas, con la conciencia de que de ello surgirá su mañana, su propia redención, su propia aurora? Por supuesto que volverá a la superficie; no le preguntéis qué es lo que busca allá abajo; él mismo os lo dirá cuando vuelva a ser hombre ese Trofonio, ese sujeto de aspecto subterráneo. Y es que quienes, como él, han vivido a solas mucho tiempo llevando una existencia de topo, no pueden permanecer en silencio. ${ }^{17} \mathrm{El}$ pensador por tanto es un perforador, un cavador, un socavador; avanza lenta, serenamente, con suave determinación. Su trabajo es metódico, perseverante. Es un trabajo de topo. Pero, ¿cuál es el objetivo de su trabajo? «En suma, la obra que yo emprendí no es apta para todos. Descendí a lo profundo, y una vez allí me puse a horadar el suelo, y empecé a examinar y a socavar una vieja fe sobre la que, durante milenios, nuestros filósofos han tratado de edificar una y otra vez como si se tratara del más sólido de los terrenos, pese a que sus edificios se han ido viniendo abajo inexorablemente. Me puse a socavar, ¿comprendéis?, nuestra fe en la moral» ${ }^{18}$.

El filósofo pretende socavar los cimientos aparentemente establecidos de manera firme sobre los que se sustenta el presente; en este caso, pretende socavar la fe en la moral platónico-cristiana como cemento universal incuestionado de una configuración histórica que más allá de una aparente pluralidad vive en un horizonte homogéneo fosilizado. La labor de topo del intelectual persigue la desfundamentación de lo aparentemente firme, la socavación de los cimientos sobre los que se asienta con una pretensión de 278).

${ }^{16}$ La genealogía de la moral, Alianza, Madrid, 1972 (=GM), I, § 12, p. 50 (KSA V 277-

${ }^{17}$ Aurora, M.E. Editores, Madrid, 1994 (=AU), Prólogo, § 1 (KSA III 11).

${ }^{18}$ AU Prólogo, §2 (KSA III 12). 
absoluta seguridad la coyuntura actual ${ }^{19}$. Ahora bien, ¿cómo practica esta desfundamentación de lo vigente?, ¿qué halla enterrado bajo estratos sedimentados desde antiguo?, ¿qué es aquello con lo que se encuentra y tiene el poder de movilizar y disolver la apariencia pétrea del presente?

Considero que el trabajo lento, metódico, de desfundamentación que Nietzsche atribuye al intelectual está vinculado al tipo de intervención epistémico-política que es la genealogía. Para comprender esto debe clarificarse evidentemente esta caracterización de la genealogía. Se trata de una intervención en tanto que el genealogista afronta la historia desde una determinada problemática, desde un determinado diagnóstico del presente que le impulsa a una aproximación a lo ocurrido interesada, nunca neutral. Su diagnóstico de la propia época actúa como horizonte constituyente de su perspectiva sobre el pasado y hace de su trabajo, por una parte, una aproximación activa sobre lo sucedido y, por otra, un movimiento de ida y vuelta: la aproximación sobre el pasado sólo tiene sentido en tanto que se consiga un efecto práctico sobre el presente.

Puede sostenerse que la genealogía es una intervención epistémica en tanto que responde expresamente a una exigencia planteada por Nietzsche, a saber: «necesitamos una crítica de los valores morales, hay que poner alguna vez en entredicho el valor mismo de esos valores -y para esto se necesita tener conocimiento de las condiciones y circunstancias de que aquellos surgieron, en las que se desarrollaron y modificaron» ${ }^{20}$. La genealogía de la moral no es otra cosa que esto: una Entstehungsgeschichte (historia de la génesis) de los valores morales que por el hecho de mostrar esto, su historia, echa por tierra la concepción tradicional de los valores, a saber la consideración del «valor de esos «valores» como algo dado, real y efectivo, situado más allá de toda duda» ${ }^{21}$,

19 Sería asunto de un trabajo aparte mostrar cómo curiosamente tanto Hegel, Marx y Nietzsche, para representar la fuerza nihilizadora de la petrificación del presente que el Espíritu, la praxis revolucionaria o el intelectual (respectivamente) poseen, utilizan la misma imagen del topo. Cf. G.W.F. Hegel, Lecciones de Historia de la Filosofía, FCE, México, 1966, y K. Marx, El 18 Brumario de Luis Bonaparte, Ariel, Barcelona, 1974, pp. 141-142. Esta imagen del topo proviene en Hegel y Marx de una escena del Hamlet de Shakespeare, mientras que en Nietzsche remite a Notas del subsuelo de F. Dostoievski. Sobre esta metáfora del topo utilizada por Nietzsche puede verse el trabajo de D.F. Krell, «Der Maulwurf. Die philosophische Wühlarbeit bei Kant, Hegel und Nietzsche», en D. O'Hara (ed), Why Nietzsche Now?, Indiana University Press, New York, 1985, pp. 155-185.

${ }^{20}$ GM Prólogo, §6, p. 23 (KSA V 253).

${ }^{21}$ Ibid. La genealogía sería una crítica «radical» de la moral, pues en tanto que ésta aspira a tener un estatuto intemporal, el genalogista «pretende recordar su génesis: la desmitifica por su historia, mejor dicho, por el hecho de tener una historia» O. Reboul, Nietzsche, crítico de Kant, Anthropos, Barcelona, 1993, p. 63. 
como algo que recibe consistencia e incuestionabilidad de su arraigo en un origen (Ursprung) metafísico fundamentador. En tanto que Entstehungs geschichte la genealogía es historia de la génesis, del surgimiento, de la emergencia de algo $^{22}$. Es la historia de ese proceso de nacimiento por el que algo comienza a ser derivándose de algo distinto. En este sentido puede sostener Foucault que la emergencia (Entstehung) es «un no lugar, una pura distancia» ${ }^{23}$, pues lo que encuentra la genealogía al comienzo no es un fundamento firme, un substrato que sirve de sustento seguro (el origen metafísico) sino lo no venerable, lo que es incapaz de servir de base y legitimación. A la base de la genealogía estaría la tesis de que «todo origen de la moral, desde el momento en que no es venerable [...] se convierte en crítica» ${ }^{24}$. Por lo tanto la genealogía es conocimiento de la génesis e historia de los valores, un conocimiento que disuelve el valor atribuido hasta ahora a los valores morales, es decir, la concepción de los valores como algo dado, real y efectivo $^{25}$. En la genealogía se alcanza una llamativa implicación mutua de conocimiento y praxis, pues el conocimiento genealógico conduce a la historización de lo que en el presente aparece como natural ${ }^{26}$. Lo propio de

\footnotetext{
${ }^{22}$ M. Foucault, «Nietzsche, la genealogía, la historia», en Microfísica del poder, La Piqueta, Madrid, 1992, p. 15.

${ }^{23}$ M. Foucault, op. cit., p. 16.

${ }^{24}$ M. Foucault, op. cit., p. 13. Una interesante discusión de la lectura de la genealogía nietzscheana por M. Foucault es llevada a cabo por J. Pizer. Su tesis, sugerente, pero que diverge de la que asumimos aquí, es que la concepción de la genealogía de Foucault exagera el papel de la discontinuidad en Nietzsche; ver J. Pizer, «The Use and Abuse of 'Ursprung': on Foucault's Reading of Nietzsche», Nietzsche-Studien, 19, 1990, p. 465. Por ello Pizer revaloriza en el planteamiento de Nietzsche el término Ursprung frente a Entstehung; op. cit., p. 466. Así en El nacimiento de la tragedia, el origen (Ursprung) de la tragedia elucidado por Nietzsche es la antítesis productiva entre lo apolíneo y lo dionisíaco; op. cit., p. 469. Ursprung no apunta en absoluto a un origen metafísico que habría que desublimar, sino que "sugiere tensión dialéctica y confrontación» (ibid); remite a un escenario de confrontación productiva de fuerzas que generan nuevas potencialidades. Con su concepción del Ursprung como mero origen metafísico Foucault pierde de vista el carácter productivo de lo antitético y de las contraposiciones en Nietzsche, lo cual, para desagrado del pensador francés, aproximaría la genealogía, según Pizer, a planteamientos de tipo dialéctico. Foucault no es capaz de ver que «la exploración del origen (Ursprung) de la moral es dialéctica»; op. cit., p. 474. Granier da un paso más en esta dirección al afirmar «la afinidad que existe entre la crítica marxista de las ideologías y el método genealógico de Nietzsche», J. Granier, Le problème de la verité dans la philosophie de Nietzsche, Editions du Seuil, Paris, 1966, p. 153.

${ }^{25}$ Cf. D. Sánchez Meca, En torno al superhombre. Nietzsche y la crisis de la modernidad, Anthropos, Barcelona, 1989, pp. 127 ss.

${ }^{26}$ En esta pretensión la genealogía converge con las articulaciones críticas de las ciencias sociales realizadas en el seno de la tradición, ciertamente plural, dialéctica materialista. Ahora bien, si la genealogía realiza una historización hacia atrás, desenterrando la historia acontecida que desmiente el carácter de en sí de lo dado en el presente, aquélla en cambio lleva a cabo una historización de su objeto hacia adelante, poniendo de manifiesto las tendencias dinámicas que lo constituyen y promueven un transcendimiento de su configuración dada en la forma de
} 
la genealogía es un «espíritu histórico» ${ }^{27}$, un «instinto histórico» ${ }^{28}$ capaz de historizar lo que se presenta como incuestionable ${ }^{29}$. La genealogía, de esta forma, sería en el Nietzsche maduro la pervivencia en el plano histórico-social del proyecto del Nietzsche ilustrado de una disciplina cognoscitiva crítica que problematizara la forma común de experiencia apelando para ello a la historia. En Humano, demasiado humano se abogaba por un tipo de conocimiento crítico que, poniendo de manifiesto el carácter devenido del modo de experiencia humana en el marco del proceso histórico-evolutivo de antropogénesis, pusiera de relieve el carácter relativo a las necesidades prácticas de la especie de la experiencia de lo real según cosas estables e idénticas reguladas según leyes subsistentes. Relativizando de esta manera su validez, posibilitaba el ahondamiento, gracias a su metodología rigurosa, en la esencia dinámica de lo real, transcendiendo con ello el horizonte de error común a la forma natural e irreflexiva de experiencia colectiva de la especie. Ahora, en La genealogía de la moral, la forma de experiencia coagulada, fruto del encandilamiento ante un presente histórico que, en un supremo acto de dominio, reclama para sí la abolición de las categorías temporales, es disuelta precisamente sacando a la luz el velado contenido histórico de la objetividad social, que aniquila su pretensión de substantividad ${ }^{30}$. La pretensión de la genealogía, como sostiene P. Veine, es disolver los «objetos naturales» en favor de las prácticas y relaciones que los constituyen y cuyo olvido los decanta como realidades cosificadas ${ }^{31}$. Este poder historizador de la genealogía ha sido defendido como uno de los pilares importantes para la orientación crítica de las ciencias sociales. Las

apertura de su cúmulo de posibles determinados. Cf. M. Horkheimer, Teoría tradicional y teoría crítica, Paidós, Barcelona, 2000, pp. 64-65, T.W. Adorno, Introducción a la sociología, Gedisa, Barcelona, 2000, pp. 191-196; J. Habermas, La lógica de las ciencias sociales, Tecnos, Madrid, ${ }^{2} 1990$, pp. 27-29.

${ }^{27} \mathrm{GM}$ I, §2, p. 30 (KSA V 258).

${ }^{28}$ GM II, §4, p. 71 (KSA V 297).

${ }^{29}$ Cf. M. Morey, «La genealogía como estilo filosófico», en VV.AA., Actualidad de Nietzsche: hacia nuevos horizontes interpretativos, Fundación Paideia, La Coruña, 1994, pp. 68 ss.; G. Cano, «Nietzsche y Foucault. La exploración genealógica como condición de posibilidad de nueva historia», Anábasis. Revista de Filosofía, 4, 1996, pp. 69 ss. Ver también M. Foucault, op. cit, pp. 13 y 27.

${ }^{30}$ Ver J.M. Romero, El caos y las formas, pp. 65 ss, 302-303, 312-313, 322-323.

${ }^{31} \mathrm{P}$. Veine, Cómo se escribe la historia. Foucault revoluciona la historia, Alianza, Madrid, 1984, p. 203. Para el genealogista, «el método consiste, por tanto, en comprender que las cosas no son más que objetivaciones de prácticas determinadas», op. cit., p. 213. Para la perspectiva de la genealogía «todos nuestros males se deben a la ilusión por la cual «cosificamos» las objetivaciones en un objeto natural», op. cit., p. 215. Según Fink «para Nietzsche la llamada objetividad de los valores no es otra cosa que una proyección realizada por la existencia, pero una proyeción olvidada», E. Fink, La filosofía de Nietzsche, Alianza, Madrid, 1976, p. 143. Sobre el papel del olvido en la experimentación de los valores como realidades objetivas, ver nota 66 . 
siguientes palabras de P. Bourdieu permiten reflexionar en qué medida Nietzsche alcanzó a establecer algunas de las condiciones del desarrollo de una ciencia social crítica: «La ciencia social, que está condenada a la ruptura crítica con las evidencias primeras, no dispone de mejor arma para llevar a cabo esa ruptura que la historización que permite neutralizar, en el orden de la teoría, por lo menos, los efectos de la naturalización y, en particular, la amnesia de la génesis individual y colectiva de un dato que se presenta con todas las apariencias de la naturaleza y exige ser aceptado sin discusiones [...]. Sólo la crítica histórica, arma capital de la introspección, puede liberar al pensamiento de las imposiciones que se ejercen sobre él cuando, dejándose llevar por las rutinas del autómata, trata como si fueran cosas unas construcciones históricas cosificadas» ${ }^{32}$.

\section{III}

La genealogía se presenta como un conocimiento que pretende ser metódico, por ello su color es «el gris, quiero decir, lo fundado en documentos, lo realmente comprobable, lo efectivamente existido, en una palabra, toda la larga y difícilmente descifrable escritura jeroglífica del pasado de la moral humana» ${ }^{33}$. La genealogía está abocada de esta manera a la «efectiva historia de la moral» ${ }^{34}$. En coherencia con esto Nietzsche estrecha la ubicación de la genealogía en relación a las ciencias, sobre todo, llamativamente, a las ciencias naturales. Afirma explícitamente que el tipo de análisis crítico de la moral que pretende realizar la genealogía requiere de una mirada plural y rigurosa que sólo determinadas ciencias particulares pueden proporcionar. Si en Humano, demasiado humano la filosofía histórica no podía pensarse «separada de la ciencia natural» ${ }^{35}$, pues su trabajo se realiza a partir del «nivel actual de las

${ }^{32}$ P. Bourdieu, Meditaciones Pascalianas, Anagrama, Barcelona, 1999, pp. 239-240. En otro lugar sostiene Bourdieu que lo que aparece en el presente social como permanente, natural y eterno es fruto de un continuado «trabajo histórico de deshistorización» por parte de determinados agentes e instituciones; P. Bourdieu, La dominación masculina, Anagrama, Barcelona, 2000, p. 104. Por lo tanto, el cuestionamiento de tales datos eternos debe tomar la forma de «la historia de los agentes y de las instituciones que concurren permanentemente a asegurar esas permanencias», op. cit., p. 105. Según Bourdieu «está claro que en la historia lo eterno sólo puede ser el producto de un trabajo histórico de eternización. En otras palabras, para escapar por completo al esencialismo no sirve de nada negar las permanencias y las invariantes que forman una parte incontestable de la realidad histórica, es preciso reconstruir la historia del trabajo histórico de deshistorización» que genera tales permanencias; op. cit., pp. 104-105. Esta podría ser una interesante definición del trabajo genealógico.

${ }^{33}$ GM Prólogo, §7, p. 24 (KSA V 254).

${ }^{34}$ Ibid. A causa de este tipo de afirmaciones, se ha creído ver un prejuicio de tipo cuasipositivista en la labor historiográfica de Nietzsche; cf. J. Jara, Nietzsche, un pensador póstumo, Anthropos, Barcelona, 1998, p. 233-234.

${ }^{35} \mathrm{HH}$ I, §1, p. 43 (KSA II 23). 
ciencias particulares» ${ }^{36}$, en La genealogía de la moral se propone en relación a la cuestión del valor de la moral y la historia de la misma una aproximación pluridisciplinar, pues la complejidad y amplitud de tal cuestión «debe ser planteada desde las más diferentes perspectivas» ${ }^{37}$. En concreto, es necesaria la aportación de «filólogos e historiadores», de «fisiólogos y médicos», asimismo de los «filósofos de oficio» que deben mediar la relación «entre filosofía, fisiología y medicina ${ }^{38}$. La genealogía se apoyaría en los resultados de esta aproximación pluridisciplinar desde diferentes ciencias a la moral considerada como problema. Por lo tanto, desde un primer momento puede reconocerse la voluntad de la genealogía por presentarse como conocimiento riguroso, cuyo objeto de conocimiento es lo realmente acaecido en la historia de la moral, lo comprobable y públicamente analizable. Un conocimiento que se presenta como analítica crítica que alcanza un elevado nivel de reflexividad crítica sobre los resultados que una aproximación pluridisciplinar aporta sobre el problemático objeto denominable como «moral».

Esta apoyatura consciente en las ciencias particulares se corresponde con la pretensión de la genealogía de hacer uso de una «metodología más adecuada ${ }^{39}$ que la que estructuraba las genealogías de la moral características de los psicólogos ingleses y que era compartida por el viejo compañero de trabajo teórico de Nietzsche que fue Paul Rée ${ }^{40}$. Pues según Nietzsche a éstos les falta el «espíritu histórico [...] todos ellos piensan de una manera esencialmente ahistórica $»^{41}$. La prueba de ello es que sostenían una continuidad esencial entre la causa, el origen de una valoración, una conducta o un código morales, y su finalidad. Así para Rée «la finalidad intimidatoria» es esencial, originaria a la pena $^{42}$, cuando lo cierto, según Nietzsche, es que «esa finalidad le fue agrega-

${ }^{36} \mathrm{HH}$ I, §1, p. 44 (KSA II 24). Y allí incluso se hacía referencia a una «ciencia que pregunta por el origen y la historia de los llamados sentimientos morales» HH I, §37, p. 66 (KSA II 59$60)$.

${ }^{37}$ GM I, $\$ 17$ nota, p. 62 (KSA V 289).

${ }^{38}$ Ibid.

${ }^{39}$ GM Prólogo, §7, p. 24 (KSA V 254).

${ }^{40} \mathrm{Se}$ ha sostenido sin embargo que el método de preguntar por el origen de las ideas morales es común entre los filósofos británicos de los siglos XVII y XVIII, que en este sentido eran ya auténticos genealogistas, como es el caso de Hume; ver D. Couzens Hoy, «Nietzsche, Hume and the Genealogical Method», en Y. Yovel, Nietzsche as affirmative Thinker, Martinus Nijhoff Publischers, Dordrecht, 1986, pp. 20-38. Las deudas de la concepción nietzscheana de la genealogía de la moral como historia natural de la moral con la pretensión de Paul Rée de realizar una ciencia empírica, positiva, de la moral son puestas de manifiesto por H. Treiber, «Zur Genealogie einer 'Science positive de la morale en Allemagne': Die Geburt der 'r(é)ealistischen Moralwissenschaft' aus der Idee einer monistischen Naturkonzeption», Nietzsche-Studien, 22, 1993, 165-221.

${ }^{41}$ GM I, §2, p. 30 (KSA V 258).

${ }^{42}$ GM Prólogo, §4, pp. 21-22 (KSA V 251). 
da [...] más tarde, en determinadas circunstancias, y siempre como algo accesorio, algo sobreañadido» ${ }^{43}$. Nietzsche cuestiona así la idea de una continuidad esencial en la historia de los valores y defiende una concepción abiertamente discontinuista que se explicita en la manera en que el origen y la forma actual de algo, su causa y su finalidad son heterogéneos, lo cual se traduce en la distinción, fundamental para la genealogía, entre la materialidad de una práctica, de un hábito, y su sentido. Concretamente habla Nietzsche acerca de: «Dos tipos de causas que se confunden. -Me parece que uno de mis pasos y progresos más esenciales ha sido aprender a distinguir entre la causa de la acción y la causa de que la acción sea de tal o cual manera, de que apunte en una dirección o hacia un fin determinados» ${ }^{44}$. Si la primera de estas causas es una fuerza largamente acumulada que se descarga en una acción, la segunda es en relación a aquélla una fuerza «completamente insignificante, un pequeño azar» ${ }^{45}$. Las finalidades, los objetivos de las acciones son «arbitrarios, casi indiferentes», sin embargo «se está habituado a ver en el fin la fuerza impulsora conforme a un antiquísimo error, cuando es sólo la fuerza directiva» ${ }^{46}$.

Ya se ha mencionado que uno de los reproches que Nietzsche efectúa sobre Rée es no haber distinguido entre procedencia (Herkunft) y la finalidad de la pena. En mitad del segundo tratado de La genealogía de la moral Nietzsche vuelve sobre esta cuestión. En un parágrafo importantísimo desde un punto de vista teórico, Nietzsche se refiere a la cuestión del «origen [Ursprung] y la finalidad de la pena dos problemas que son distintos o deberían serlo: por desgracia, de ordinario se los confunde ${ }^{47}$. Y han caído ingenuamente en esta confusión los genealogistas de la moral existentes hasta el momento que «descubren en la pena una «finalidad» cualquiera, por ejemplo, la venganza o la intimidación, después colocan despreocupadamente esa finalidad al comienzo, como causa fiendi [causa productiva] de la pena y -ya han acabado $»^{48}$. Sin embargo, para Nietzsche, la Entstehungsgeschichte que es la genealogía debe renunciar a tal papel explicativo concedido a la finalidad, pues se sostiene en una “metódica histórica» cuyo «punto de vista capital» ${ }^{49}$, el cual es el «principio más importante para toda especie de ciencia histórica», sostiene que «la causa de la génesis de una cosa y la utilidad final de ésta, su efectiva utilización e inserción en un sistema de finalidades, son hechos toto coelo [totalmente] separados entre sí; que algo existente, algo que de algún modo ha llegado a

\footnotetext{
${ }^{43}$ GM Prólogo, §4, p. 22 (KSA V 251).

${ }^{44}$ GC $\$ 360$ (KSA III 607).

${ }^{45}$ Ibid.

${ }^{46}$ Ibid.

${ }^{47}$ GM II, §12, p. 87 (KSA V 313).

${ }^{48}$ Ibid.

${ }^{49}$ GM II, §12, p. 89 (KSA V 315).
} 
realizarse, es interpretado una y otra vez, por un poder superior a ello, en dirección a nuevos propósitos, es apropiado de un modo nuevo, es transformado y adaptado a una nueva utilidad; que todo acontecer en el mundo orgánico es un subyugar, un enseñorearse, y que, a su vez, todo subyugar y enseñorearse es un reinterpretar, un reajustar, en los que, por necesidad, el 'sentido' anterior y la 'finalidad' anterior tienen que quedar oscurecidos o incluso totalmente borrados» ${ }^{50}$.

La causa no se imprime sobre lo generado de manera indeleble determinando su forma y sentido permanentemente, no es algo que va desplegando su sentido plasmándose y madurando en la historia de la práctica o de una cosa en general. La historia de una cosa no remite a una identidad esencial que marca su nacimiento y su desarrollo hasta su forma actual. Desde la perspectiva de Nietzsche debe abandonarse tal concepción continuista de la historia. El conocimiento histórico propuesto por él según esta metódica atiende a las discontinuidades de la historia de la cosa, en concreto a la serie sucesiva de apropiaciones violentas de la misma por poderes diversos que han llevado a cabo sobre ella una reubicación en un marco distinto otorgándole una utilidad, una finalidad y un sentido diferentes: «todas las finalidades, todas las utilidades son sólo indicios de que una voluntad de poder se ha enseñoreado de algo menos poderoso y ha impreso en ello, partiendo de sí misma, el sentido de una función; y la historia entera de una (cosa), de un órgano, de un uso, puede ser así una ininterrumpida cadena indicativa de interpretaciones y reajustes siempre nuevos, cuyas causas no tienen siquiera necesidad de estar relacionadas entre sí, antes bien a veces se suceden y se relevan de un modo meramente causal» ${ }^{51}$. Se trata por tanto de un proceso de reinterpretación constante que implica que las interpretaciones pasadas, los sentidos anteriormente conferidos queden encubiertos, invisibles, bajo los estratos recientemente añadidos. Esto, como decimos, introduce un momento de discontinuidad esencial en la historia y nihiliza la noción clásica de progreso como desarrollo lógico hacia una meta: «El 'desarrollo' [Entwicklung] de una cosa, de un uso, de un órgano es, según esto, cualquier cosa antes que su progressus hacia una meta, y menos aún un progreso lógico y brevísimo, conseguido con el mínimo gasto de fuerza y de costes, sino la sucesión de procesos de avasallamiento más o menos profundos, más o menos independientes entre sí, que tienen lugar en la cosa, a lo que hay que añadir las resistencias utilizadas en cada caso para contrarrestarlos, las metamorfosis intentadas con una finalidad de defensa y de reacción, así como los resultados de contra-acciones afortunadas. La forma es fluida, pero el 'sentido' lo es todavía más...» ${ }^{52}$.

${ }^{50}$ GM II, §12, pp. 87-8 (KSA V 313-314).

${ }^{51}$ GM II, §12, p. 88 (KSA V 314).

${ }^{52}$ GM II, §12, pp. 88-89 (KSA V 314-315). 
Este «punto de vista capital de la metódica histórica ${ }^{53}$ es antagónico de toda concepción teleológica de la historia. La historia no es sino «la sucesión de procesos de avasallamiento» sobre una cosa junto con «las resistencias» que se han puesto en juego contra tales violentaciones. Ningún sentido, ningún telos se plasma en la historia. La única causalidad histórica es la constituida por la diferente correlación de fuerzas entre los grupos enfrentados en el escenario social y que determina, en la realización efectiva de la confrontación, quién impone su régimen de dominio y se apropia de las prácticas socialmente vigentes imprimiéndoles un sentido funcional a tal régimen. Además de esa distinción entre causa y finalidad de una cosa, de una práctica, de una prescripción, Nietzsche distingue en la pena, como prototipo de las prácticas de tipo moral, «dos cosas: por un lado, lo relativamente duradero en la pena, el uso, el acto, el «drama», una cierta secuencia rigurosa de procedimientos; por otro lado, lo fluido en ella, el sentido, la finalidad, la expectativa vinculados a la ejecución de tales procedimientos $»^{54}$. Lo relativamente permanente en la práctica es el acto material mismo, el protocolo, la sucesión medida de acciones determinadas y codificadas. El «elemento fluido» es «su sentido» ${ }^{55}$, aquello aportado por cada régimen de poder que hace suya, que se asimila la práctica concreta. La tesis de Nietzsche es, «de acuerdo con el punto capital de la metódica histórica que acabamos de exponer, que el procedimiento mismo será algo más viejo, algo más antiguo que su utilización para la pena, que ésta última ha sido introducida posteriormente en la interpretación de aquél» ${ }^{56}$. El sentido es añadido a posteriori y de una manera completamente externa a la práctica respecto a la cual es plenamente contingente. Nietzsche se esfuerza en «dar al menos una idea de cuán inseguro, cuán sobreañadido, cuán accidental es «el sentido» de la pena, y cómo un mismo e idéntico procedimiento se puede utilizar, interpretar, reajustar para propósitos radicalmente distintos $»^{57}$. Nietzsche, de esta forma, posibilita una distinción crítica entre la materialidad de una práctica y su sentido, el cual está vinculado a quién, qué perspectiva, qué tipo de fuerza, se ha asimilado la práctica en cuestión poniéndola a su servicio en un determinado contexto y en una problemática específica. El sentido de una práctica remite a quién la hace suya en una determinada situación, a qué finalidad la somete ${ }^{58}$. Esto le permite a Nietzsche en principio sustentar una posición capaz de rescatar determinadas prácticas del uso que de ellas se ha realizado en la tradición platónico-cristiana emancipándolas del monopo-

${ }^{53}$ GM II, §12, p. 89 (KSA V 315).

${ }^{54}$ GM II, §13, p. 90 (KSA V 316).

${ }^{55}$ GM II, §13, p. 91 (KSA V 317).

${ }^{56} \mathrm{GM} \mathrm{II,} \$ 13$, p. 90 (KSA V 316).

${ }^{57}$ GM II, §13, p. 91 (KSA V 317).

${ }^{58}$ Nietzsche demuestra esto en relación al ideal ascético, ver GM III, p. 113 ss. (KSA V 349ss). 
lio interpretativo que aquélla se atribuyó. Pero, de un modo más esencial, este sustento metodológico permite a Nietzsche reforzar una perspectiva analítica histórica capaz de percibir las profundas discontinuidades que marcan el decurso histórico aboliendo la idea de un progreso continuista ${ }^{59}$. Se trata de una analítica apta para comprender en qué medida regímenes y dispositivos de poder han intervenido en la constitución de lo histórico y han conferido el carácter de evidencia a nuestro presente.

Este sustento metodológico posibilita que la genealogía, en su empeño en historizar lo indiscutible, acceda a su verdad reprimida, a una verdad que al ser rescatada provoca todo un «ruido endiablado» ${ }^{60}$, una verdad que respecto a lo sacralizado en el presente es una blasfemia ${ }^{61}$. Esta verdad no es sino su historia $^{62}$. Gracias a su capacidad historizadora, conferida por su soporte metodológico, la genealogía ahonda realmente en verdades veladas que para el presente constituyen un escándalo. Efectivamente, Nietzsche desea que los genealogistas de la moral «sean en el fondo animales valientes, magnánimos y orgullosos, que saben mantener refrenados tanto su corazón como su dolor y que se han educado para sacrificar todos sus deseos a la verdad, a toda verdad, incluso a la verdad simple, áspera, fea, repugnante, no-cristiana, no-moral... Pues existen verdades tales ${ }^{63}$. El contenido de esta verdad obscena es la historia de los valores (y, en definitiva, la historia del presente) cuya sustancia consiste en el conflicto, en el desnudo antagonismo entre determinados grupos humanos que, al no estar decidido su resultado de antemano, confiere a la historia una discontinuidad esencial. De esta forma los valores son reconocidos como materia dúctil al servicio de grupos humanos concretos en su confrontación con otros grupos en el marco de un proceso histórico constituido por la guerra, la explotación, las relaciones de dominio, la voluntad de poder ${ }^{64}$, es de-

${ }^{59}$ Desde unos parámetros intelectuales diferentes también Rosenzweig, Benjamin y Scholem concibieron la historia, frente a las concepciones centradas en la categoría de progreso, a partir de la idea de discontinuidad; cf. S. Mosès, El ángel de la historia. Rosenzweig, Benjamin, Scholem, Cátedra, Madrid, 1997, pp. 21 ss.

${ }^{60}$ Crepúsculo de los ídolos, Alianza, Madrid, 1973, p. 52 (KSA VI 81).

${ }^{61}$ AU $§ 1$ (KSA III 19).

${ }^{62}$ Es aquí donde la presente lectura de la genealogía discrepa con la que realiza M. Foucault, en tanto que para él la genealogía no puede ser considerada como conocimiento y está desvinculada de toda verdad; M. Foucault, op. cit. p. 25 y 27, respectivamente. Para un contraste con la concepción deleuziana de la genealogía ver G. Deleuze Nietzsche y la filosofía, Anagrama, Barcelona, 1986, pp. 134 ss.

${ }^{63} \mathrm{GM} \mathrm{I}, \S 1$, p. 30 (KSA V 258). Cf. GM II, §4, p. 71 (KSA V 297).

${ }^{64}$ Ver E. Fink, op. cit., pp. 152-153; M. Heidegger, «La frase de Nietzsche "Dios ha muerto"», en Caminos de bosque, Alianza, Madrid, 1995, pp. 172 ss. y Nietzsche, Pfullingen, 1961, vol. II, pp. 89 ss. (trad. cast. Destino, Barcelona, 2000, vol. II, pp. 77 ss). La genealogía nietzscheana debe ser ubicada en relación a lo que Foucault denominaba discurso de la guerra que nace en Europa entre el siglo XVI y XVII y que dio lugar en el siglo XIX a formas de historia no legitimistas, que Foucault denomina como contrahistorias. Este discurso de la guerra 
cir, por una irracionalidad esencial que disuelve el carácter de realidades en sí atribuido a los valores morales. Esta irracionalidad constitutiva de la historia es la verdad sacada a la luz por la genealogía. Para Nietzsche, efectivamente, «en la Historia [...] la regla es la irracionalidad del azar» ${ }^{65}$.

\section{IV}

También he sostenido que la genealogía es una intervención epistémicopolítica. Ya se ha expuesto cuál es el punto de partida problemático de Nietzsche: los valores morales han sido concebidos por la moral platónicocristiana como realidades objetivas, subsistentes, con existencia independiente de los individuos $\mathrm{y}$, por tanto, como algo incuestionable. La sociedad moderna, heredera en lo esencial de la sociedad y cultura platónico-cristiana, pretende asentarse, utilizando tales valores como cimientos firmes, con una legitimidad absoluta, problematizando completamente la idea de un posible transcendimiento de sí misma. Afianzada en unos valores considerados eternos la sociedad moderna pretende ser la culminación intranscendible de una historia que conduciría inevitablemente a ella. Asentada sobre tales cimientos, la sociedad burguesa, fin en los dos sentidos de la historia, podría reconstruir todo el proceso histórico como conducente a su realización y por lo tanto como un proceso racional que en tanto que culmina en la sociedad vigente hace de ésta la realización plena de lo racional: identidad efectiva de realidad y razón. Es decir, marco hermético, intranscendible, en tanto que efectiva realización de toda posibilidad históricamente pensable.

En relación a esto el efecto de la genealogía es fundamentalmente político. Pues la verdad sacada a la luz por la genealogía, la irracionalidad constitutiva de la historia, desfundamenta de principio la pretensión del mundo burgués de ser identidad efectiva de realidad y racionalidad y hace de la historia un proceso carente de teleología, un proceso impulsado por el conflicto en relación al cual el presente es la realización de uno de los posibles que tal proceso contenía, realización efectuada en virtud de la particular correlación de fuerzas existente en un determinado momento histórico ${ }^{66}$. La verdad rescatada por la genealogía

considera que «la guerra es la que constituye el motor de las instituciones y del orden: la paz, hasta en sus mecanismos más ínfimos, hace sordamente la guerra. En otras palabras, detrás de la paz se debe saber descubrir la guerra; la guerra es la clave misma de la paz. Estamos entonces en guerra los unos contra los otros: un frente de batalla atraviesa toda la sociedad, continua y permanentemente, poniendo a cada uno de nosotros en un campo o en otro» M. Foucault, Genealogía del racismo, La Piqueta, Madrid, 1994, p. 59.

${ }^{65}$ KSA XI 58, Frühjahr 1884, 25[166].

${ }^{66}$ A partir de lo expuesto puede sostenerse que la reificación de los valores como cosas subsistentes contrapuestas inflexiblemente a toda praxis no se sustenta en un presunto olvido antropológicamente esencial. Es la coagulación de las luchas, de los conflictos, que han 
tiene como efecto una desfundamentación radical de la sociedad moderna ${ }^{67}$. Disuelve su carácter petrificado, su carácter cerrado. El efecto de la verdad de la genealogía es por tanto fluidificar, historizar el presente permitiendo la apertura de nuevas posibilidades transcendentes al mismo: abre el horizonte de posibles al pensar y actuar humanos ${ }^{68}$. Éste es el interés político esencial del genealogista que hace de su trabajo una auténtica intervención que aspira a tener un efecto práctico sobre los agentes abocados a una praxis aquí y ahora ${ }^{69}$.

La verdad de la historia salvada por la genealogía abre una brecha en esa identidad entre realidad y racionalidad con la que el último Hegel había elevado al Estado burgués a encarnación de Dios en la tierra. Efectivamente, vuelve a abrir una cesura en la conciliación efectiva de lo real y lo racional con la que Hegel petrificó la dialéctica ${ }^{70}$. Esa cesura, esa brecha, permite problematizar las posiciones apologistas respecto al presente y posibilita una percepción fluida del mismo, sensible a los factores dinámicos, las luchas no clausuradas, que lo constituyen. La irracionalidad constitutiva de la historia disuelve la falsa sus-

constituido el curso histórico, decantando el presente como fijación del dominio de uno de los bandos enfrentados, lo que confiere de hecho a los valores, más allá de su experimentación por parte de los sujetos como realidades en sí, su poder efectivo sobre los individuos. Es un determinado trasfondo marcado por una específica asimetría petrificada en la relación de poder entre los grupos enfrentados lo que posibilita la idealización de los valores como realidades consistentes. El olvido que da pie a la cosificación tiene como sustento una coerción estructural efectiva que respalda con la amenaza de la violencia la validez de tales valores.

${ }^{67}$ Según Löwith, Nietzsche se propuso un análisis «radical» de «la decadencia del mundo cristiano-burgués»; K. Löwith, De Hegel a Nietzsche, Sudamericana, Buenos Aires, 1968, p. 247. En palabras de Vattimo, la de Nietzsche es una «rebelión contra la tradición y las instituciones teóricas y prácticas del mundo cristiano-burgués realizada aún desde el interior de este mismo mundo con los instrumentos disponibles en él», G. Vattimo, El sujeto y la máscara, Península, Barcelona, 1989, p. 312. El no haber visto este momento crítico del irracionalismo de Nietzsche respecto a la sociedad burguesa constituye el problema fundamental de la lectura de Lukács que le posibilita hacer de Nietzsche el legitimador del capitalismo en su fase imperialista, cf. G. Lukács, El asalto a la razón, Grijalbo, México, 1968, pp. 259 ss.

${ }^{68} \mathrm{El}$ «contenido fundamental del método genealógico [es] la apertura a las muchas posibilidades del devenir humano», G. Vattimo, op. cit., p. 137. Ya para J. Burckhardt, tan admirado por el joven Nietzsche, «el conocimiento del pasado es lo único que puede hacer al hombre libre del imperio que, por medio de los símbolos, ejercen sobre él los usos sociales», J. Burckhardt, Reflexiones sobre la historia universal, FCE, México, ${ }^{2} 1961$, p. 50. Según S. Kemal, la genealogía subvierte la creencia en que los valores son comprehensivos, racionales o universales. Como resultado, abre la vía a la creación de valores en la plena conciencia del hecho de que son sintomáticos de una perspectiva; S. Kemal, «Some Problems of Genealogie», Nietzsche-Studien, 19, 1980, p. 31.

${ }^{69} \mathrm{~J}$. Conill pone de manifesto la tendencia del último Nietzsche a una fusión de teoría y práctica; ver J. Conill, El poder de la mentira. Nietzsche y la política de la transvaloración, Tecnos, Madrid, 1997, pp. 158 ss.

${ }^{70}$ Ya Adorno hizo referencia a la «interrupción de la dialéctica por parte de Hegel» T.W. Adorno, Dialéctica negativa, Taurus, Madrid, 1975, pp. 332 ss. 
tantividad del presente mostrándolo como frágil configuración sometida a un indomeñable devenir ${ }^{71}$. Ciertamente, un devenir sin dirección prefijada, sin lógica predefinida. Pero la sustancia irracional sobre la que el mundo cristiano-burgués se sostiene como un durmiente «pendiente en sus sueños del lomo de un tigre ${ }^{72}$, desborda, sobrepasa, como una desmesura incontrolable e inasimilable, tal marco, definido presuntamente de una vez por todas, que pretendía delimitar con la efectividad de un bisturí qué posibilidades históricas nos son siquiera imaginables. En la exhumación de tal verdad, el filósofo, en su labor de genealogista, alcanza un máximo antagonismo en relación a su época. El trabajo subterráneo de topo está, de esta forma, encauzado a la apertura de porvenir ${ }^{73}$. Este escarbar bajo la acumulación de estratos que dan consistencia a nuestro hoy es una labor preñada de futuro. Efectivamente, este peculiar topo, como quería Nietzsche, refleja el futuro en su rostro ${ }^{74}$.

\section{V}

Esta tesis, a saber, que la sociedad vigente se sustenta problemáticamente en un sustrato de irracionalidad que es incapaz de asimilar o eliminar y que nihiliza toda pretensión de sustantividad por su parte, constituye el momento, en el planteamiento de Nietzsche, de máxima crítica respecto al mundo moderno. En tanto que apunta al fundamento-desfundamentador de la sociedad moderna se autopercibe como una crítica radical. Pero, sin embargo, en esta misma pretensión de radicalidad reside el límite y la ambigüedad del posicio-

${ }^{71}$ En relación a esto, sostiene Klossowski: «En tanto que impulso primordial, la voluntad de poder es el término que debe expresar la fuerza misma [...] exige, por su naturaleza, que se rompa la conservación de un nivel alcanzado y que, por lo tanto exceda siempre este nivel creciendo con absoluta necesidad. De esta manera la voluntad de poder aparece como un principio de desequilibrio, para todo aquello que quería ser duradero a partir de un cierto grado, sociedad o individuo» P. Klossowski, Nietzsche y el círculo vicioso, Seix Barral, Barcelona, 1972, p. 153.

${ }^{72}$ «Sobre verdad y mentira en sentido extramoral», en F. Nietzsche - H. Vaihinger, Sobre verdad y mentira, Tecnos, Madrid, 1990, p. 20 (KSA I 877).

${ }^{73}$ Ahora bien, debe señalarse que la genealogía de la moral, en manos de Nietzsche, no aspira propiamente a la apertura de un espacio de libertad para la decisión y la praxis colectivas. Está al servicio de una importantísima tarea que Nietzsche desvincula del plano común, público, de elucidación y decisión y otorga únicamente al filósofo. El déficit democrático de esta posición y la asimilación de reminiscencias de la concepción platónica del filósofo se pone de manifiesto en que en el planteamiento de Nietzsche la genealogía, en tanto que nihilización de la consistencia de los valores establecidos, es la condición de posibilidad de «la tarea futura del filósofo: entendida esta tarea en el sentido de que el filósofo tiene que solucionar el problema del valor, tiene que determinar la jerarquía de los valores» GM I, p. 62 nota (KSA V 289). Esta tarea del filósofo «exige que él cree valores.» MB §211, p. 155 (KSA V 144).

${ }^{74}$ Sobre la centralidad de la categoría de futuro en la concepción nietzscheana del acercamiento cognoscitivo al pasado, ver V. Depkat, «Ungeschichtlicher Geschichtbezug», Nietzsche-Studien, 29, 2000, pp. 318 ss. 
namiento crítico nietzscheano respecto a la sociedad existente. Pues, para Nietzsche, el hecho de que la verdad de la historia sea la irracionalidad de la voluntad de poder significa que la guerra, la explotación, las relaciones de dominio son la esencia inmodificable de la historia. En Más allá del bien y del mal podemos leer: «la vida es cabalmente voluntad de poder. En ningún otro punto, sin embargo, se resiste más aquí a ser enseñada la consciencia de los europeos: hoy se fantasea en todas partes, incluso bajo disfraces científicos, con estados venideros de la sociedad en los cuales 'el carácter explotador' desaparecerá: a mis oídos esto suena como si alguien prometiese inventar una vida que se abstuviese de todas las funciones orgánicas. La 'explotación' no forma parte de una sociedad corrompida o imperfecta y primitiva: forma parte de la esencia de lo vivo, como función orgánica fundamental, es una consecuencia de la auténtica voluntad de poder, la cual es cabalmente la voluntad propia de la vida. -Suponiendo que como teoría esto sea una innovación, como realidad es el hecho primordial de toda historia» ${ }^{75}$. Aquí parecemos encontrarnos con una paradoja en el planteamiento de Nietzsche. Pues su estrategia en tanto que genealogista es historizar el presente y desfundamentar su pretensión de intranscendibilidad, es decir, de ser un marco eterno, permanente. De ahí que arremeta contra lo que servía de sustento a su cristalización: la existencia de unos valores eternos, inmutables, auténticos pilares, en sentido literal, de la tradición occidental y de la sociedad existente. Pero a lo que asistimos es que en tal historización del presente, tras la fluidificación de los valores, las formas institucionales, culturales y políticas, paradójicamente retorna como mismidad insuperable, como fondo parmenídeo, el hecho bruto y primordial de la explotación, la violencia, el dominio. Podría sostenerse que al devenir nietzscheano está íntimamente vinculado una insuficiente tematización de la historia, pues la afirmación de un devenir y un fluir históricos contra toda falsa sustantivación del presente es conjugado con una devaluación de lo histórico en tanto que éste aparece radicalmente limitado ante un fondo primordial no historizable: una violencia e irracionalidad originarias que el eterno devenir de formas no hace más que reproducir incesantemente $^{76}$. Efectivamente, para Nietzsche la voluntad de poder, en tanto que «carácter inteligible» del mundo ${ }^{77}$, es la esencia profunda e inmodificable de la historia, y asume en su pensamiento ético y político una posición nor-

${ }^{75}$ MB $§ 259$, p. 222 (KSA V 208).

${ }^{76} \mathrm{~W}$. Kuhmann sostiene respecto al «hecho primordial de la historia», hipostasiado en Más allá del bien y del mal, que la voluntad de poder tiene el papel de auténtica «categoría mítica»; W. Kuhmann, Die Rückkehr des Täuschenden Scheins der Dinge, Pahl-Rugenstein Verlag, Köln, 1986, pp. 303 ss. En consecuencia se puede hablar de un «eterno retorno del poder», GG. Grau, Ideologie und Wille zur Macht. Zeitgemässe Betrachtungen über Nietzsche, Walter de Gruyter, Berlin/New York, 1984, p. 172.

${ }^{77} \mathrm{MB} \S 36$, p. 62 (KSA V 55). 
mativa ${ }^{78}$. La genealogía estaría sometida así a un movimiento paradójico. Aplica una mirada historizadora sobre los valores morales que permite que dejen de ser percibidos como realidades consistentes y puedan ser constatados como productos históricos generados a partir del ámbito de los conflictos que estructuran las relaciones entre los grupos humanos antagónicos. Pero como substrato de todo este proceso que denominamos historia remite a una esencia de tipo metafísico que «se despliega en todo acontecer» ${ }^{79}$, hace inteligible lo histórico y constituye el acontecer originario de toda historia posible ${ }^{80}$. La historia resulta así concebible como un proceso natural, un proceso sometido a la misma legalidad que impera en el mundo animal e inerte, a saber: «todo poder saca en cada instante su última consecuencia» ${ }^{81}$. Lo que podría ser entendido como constatación crítica de que la historia humana es, a pesar de las pretensiones de los legitimistas del presente burgués, todavía mera prehistoria o una forma de historia natural, resulta en cambio en manos de Nietzsche una tesis apologista respecto a la irracionalidad existente. Pues tal caracterización de la historia humana como ámbito de despliegue de una voluntad de poder esencial sirve de base normativa para descalificar toda fórmula política democrática y aspirante a la generación de grados más altos de justicia social como nihilista, como contraria a la esencia de la vida y de lo real en su totalidad. «Abstenerse mutuamente de la ofensa, de la violencia, de la explotación: [...] tan pronto como se quisiera extender ese principio e incluso considerarlo, en lo posible, como principio fundamental de la sociedad, tal principio se mostraría en seguida como lo que es: como voluntad de negación de la vida. Aquí resulta necesario pensar a fondo y con radicalidad y defenderse contra toda debilidad sentimental: la vida misma es esencialmente apropiación, ofensa, avasallamiento de lo que es extraño y más débil, opresión, dureza, imposición de formas propias, anexión y al menos, en el caso más suave, explotación» ${ }^{82}$.

Puede parecer problemático que se atribuya a Nietzsche la paradójica posición de afianzar un fondo inmodificable, no historizable, como esencia de lo histórico, pues podría responderse que el pensador alemán concibe como esencia de la historia la voluntad de poder, es decir, algo esencialmente dinámico, que el mismo Nietzsche define como incesante tendencia a la

${ }^{78}$ Cf. MB $\S 186$, p. 115 (KSA V 106-107).

${ }^{79}$ GM II, §12, p. 89 (KSA V 315).

${ }^{80}$ En otro lugar he sostenido que puede proponerse que la genealogía nietzscheana afronta la historia y el presente como un ámbito ya interpretado como voluntad de poder y es por ello víctima de la pretensión de alcance metafísico del Nietzsche maduro de llevar a cabo una interpretación de todo acontecer como tal voluntad de poder, ver J.M. Romero, El caos y las formas, pp. 304-305.

${ }^{81} \mathrm{MB} \S 22$, p. 45 (KSA V 37).

${ }^{82}$ MB §259, pp. 221-222 (KSA V 207-208). Ver también GM II, §11, p. 87 (KSA V 313). 
autosuperación ${ }^{83}$, a la creación de «unidades mayores de poder» ${ }^{84}$. Efectivamente, podría resultar llamativo que se critique a Nietzsche el postular como esencia inmodificable de lo real histórico su ser dinámico. La cuestión es más compleja que esta simple constatación, pues la esencia de lo histórico no es caracterizada por Nietzsche como mero devenir. Como se ha visto, la voluntad de poder posee en el planteamiento nietzscheano un contenido muy concreto: «en sí, ofender, violentar, despojar, aniquilar no puede ser naturalmente «injusto» desde el momento en que la vida actúa esencialmente, es decir, en sus funciones básicas, ofendiendo, violando, despojando, aniquilando, y no se la puede pensar en absoluto sin ese carácter ${ }^{85}$. Es este contenido no justificado atribuido a la voluntad de poder lo que constituye el núcleo natural, no historizable de la realidad histórica. Es lo que como una maldición retorna eternamente en lo histórico, lo que hace necesariamente de la historia en tanto que tal proceso natural, para una perspectiva que Nietzsche evidentemente no podría compartir, algo análogo a un infierno ${ }^{86}$.

La voluntad de poder parece incluir en el planteamiento de Nietzsche dos momentos en principio antitéticos: por un lado, le es esencial, como se ha apuntado, la tendencia incesante a la autosuperación, a la generación de plasmaciones de sí cada vez más poderosas ${ }^{87}$. Es propio de ella la actividad, el crecimiento, la expansión, el sobrepasamiento de cualquier obstáculo, de cualquier consolidación, que pueda suponer un encorsetamiento de su tendencia a devenir más poder. De manera que la mera conservación, la mera adaptación es contraria a la esencia de la voluntad de poder ${ }^{88}$. Por otra parte, sin embargo, es constitutiva de la voluntad de poder (es su «función orgánica fundamental») el violentar, el despojar, el aniquilar y el hecho de la explotación. Todo ello aparece como lo permanente, como factor estático que se mantiene imperturbable frente a todo dinamismo. De esta inconsistencia sólo podría librar al pensamiento de Nietzsche un intérprete versado en las artes interpretativas de la tradición hegeliana que fuera capaz de vislumbrar en esta contradicción el momento de verdad que posee un planteamiento que no sería sino la elevación a concepto del contenido esencial de la época (la de Nietzsche, la nuestra) de la que es fruto.

${ }^{83}$ Así habló Zaratustra, Alianza, Madrid, 1972, p. 171 (KSA V 148).

${ }^{84}$ GM II, §11, p. 87 (KSA V 313).

${ }^{85}$ GM II, §11, pp. 86-87 (KSA V 312).

${ }^{86}$ Cf. W. Benjamin, Das Passagen-Werk, Suhrkamp, Frankfurt am Main, ${ }^{2} 1998$, vol. 2, pp. 1010-1011.

${ }^{87}$ Una aproximación al carácter complejo y, si se es fiel a la diversidad de formulaciones que aparecen en determinados textos de Nietzsche, plural de la concepción nietzscheana de la voluntad de poder es realizada en J.M. Romero, op. cit., pp. 180-196 y 222-229.

${ }^{88}$ GM II, §12, pp. 89-90 (KSA V 315-316). La interpretación heideggeriana hizo hincapié en esta cuestión; ver M. Heidegger, Nietzsche, vol. I, p. 473 ss. (ed. cast., vol. I, pp. 383 ss.). 
La concepción esencializada de la voluntad de poder, substrato de la historia y del presente, es la raíz de la problemática ubicación política de Nietzsche y el sustento de la compatibilidad de algunas de sus propuestas con posiciones políticas calificables como salvajes ${ }^{89}$. En esta cuestión Nietzsche no está a la altura de sus propias reflexiones anteriores. El último Nietzsche lamentablemente no se atuvo a la tesis con la que abría Humano, demasiado humano: «todo ha devenido; no hay datos eternos, lo mismo que no hay verdades absolutas. Por eso de ahora en adelante es necesario el filosofar histórico y con éste la virtud de la modestia ${ }^{90}$. De esta forma, la tarea de pensar con Nietzsche y hacer su pensamiento productivo para nuestro horizonte práctico pasa necesariamente por un inexorable trabajo de pensar contra Nietzsche volviendo contra él incluso los resultados productivos de su propia reflexión. Sostuvo Adorno que puede concebirse como la tarea esencial y más propia de la Ilustración la disolución de todo encantamiento, de todo fetichismo, que someta a las conciencias a la fuerza mágica conferida bien a poderes externos al ser humano, o autonomizados de él o bien a las propias relaciones sociales que sostienen una estructura social que somete a la mayoría de los seres humanos a una situación de indignidad material, intelectual y moral ${ }^{91}$. Si se acepta esto, el trabajo crítico de Nietzsche contra la metafísica, la religión y la moral tradicional puede ser considerado como ejemplarmente ilustrado. Sin embargo, el pensamiento de Nietzsche cae en un postrero fetichismo: la instauración de la voluntad de poder como esencia originaria de la historia, la cual es en sus manos una instancia antagónica respecto a toda categoría de universalidad que incluya también a los menos capacitados para la lucha por la autosuperación (o que simplemente renuncian a ello) como miembros de una comunidad regulada por criterios de justicia ${ }^{92}$. Al dejar incólume ese núcleo mistificado de

\footnotetext{
${ }^{89}$ Ver los importantes trabajos de R. Safranski, «Nietzsche superhombre. Teatro de cámara o drama mundial», Revista de Occidente, 226, 2000, 7-22 y Friedrich Nietzsche. Biografía de su pensamiento, Tusquets, Barcelona, 2001, pp. 44 ss.; L.E. de Santiago Guervós, «Arte y política: El dionisismo político del joven Nietzsche», en VV.AA., Política, historia y verdad en la obra de F. Nietzsche, Huerga Fierro editores, Madrid, 2000, pp. 193-218. Para una lectura discrepante de la aquí sostenida, ver M. Barrios, La voluntad de poder como amor, Ediciones del Serbal, Barcelona, 1990.

${ }^{90} \mathrm{HH}$ I, §2, p. 44 (KSA II 25). Sobre la filosofía histórica propuesta por Nietzsche en Humano, demasiado humano, como analítica histórica y como forma de ilustración, ver A. Lafranconi, Nietzsches historische Philosophie, Frommann-Holzboog, Stuttgart, 2000, sobre todo pp. 160-161.

${ }^{91}$ Cf. T. W. Adorno, «Sobre la lógica de las ciencias sociales», en T.W. Adorno y otros, $L a$ disputa del positivismo en la sociología alemana, Grijalbo, México, 1973, p. 138.

${ }^{92}$ Respecto a los «utilitaristas ingleses» afirma Nietzsche que «ninguno de esos animales de rebaño (...) quiere saber ni oler nada de que el «bienestar general» no es un ideal, ni una
} 
la historia que es la voluntad de poder, acaba frustrándose la historización del carácter hermético del presente y la apertura del horizonte de posibilidades que la genealogía pretendía. Con esta fetichización, el trabajo ilustrado nietzscheano, como diría Adorno, «comete sabotaje contra sí mismo» ${ }^{93}$.

El Nietzsche maduro no fue quizás enteramente desleal a la tarea de la filosofía propugnada por él en la cuarta Intempestiva (1876): «La cuestión más importante para toda filosofía me parece ser averiguar hasta qué punto las cosas tienen una forma y un carácter inmutable, para poder luego, cuando esta cuestión haya sido resuelta, perseguir con ardor a toda prueba el mejoramiento de lo que en este mundo es concebido como susceptible de cambio ${ }^{94}$. Pero es muy posible que él mismo introdujera en el carácter inmutable de las cosas, en la esencia de la vida y del mundo, factores que poseen, según la irónica expresión del propio Nietzsche, un origen humano, demasiado humano.

meta, ni un concepto aprehensible de algún modo, sino únicamente un vomitivo, de que lo que es justo para uno no puede ser de ningún modo justo para otro, de que exigir una moral para todos equivale a lesionar cabalmente a todos los hombres superiores, en suma, de que existe un orden jerárquico entre un hombre y otro hombre» MB §228, p. 175 (KSA V 165-165).

${ }^{93}$ T.W. Adorno, op. cit.

${ }^{94}$ Richard Wagner en Bayreuth, en Obras Completas, Aguilar, Madrid, 1966, vol. I, §3, p. 205 (KSA I 445). 